ERRATA IN THE TABLES.

\begin{tabular}{|c|c|c|c|c|}
\hline Page & Age & Column & Error & Correction \\
\hline 498 & 0 & $\Delta$ Colog $p_{x}$ & 0.96353 & $\overline{1} \cdot 96353$ \\
$3 "$ & 13 & $\#$ & 00000 & $0 \cdot 00000$ \\
505 & 61 & $\mathbf{R}_{x}$ & $73314 \cdot 37$ & 77314.37 \\
547 & 90 & $\mathrm{~A}_{x}$ & .84512 & .85412 \\
\hline
\end{tabular}

\title{
THE LEGAL STAMP DUTY ON RE-ASSURANCE POLICIES, EFFECTED BY WAY OF GUARANTEE ON A COPY OF THE ORIGINAL POLICY.
}

To the Editor of the Journal of the Institute of Actuaries.

Sin,-Up to the present it has been, I believe, the general practice to stamp re-assurances in the same way as direct policies, the result being that the Government receive double stamp duty on the amount re-assured.

This society has recently obtained an adjudication of the proper stamp which should be placed on re-assurances, effected by way of guarantee on a copy of the original policy, and it would appear that a sixpenny stamp is legally sufficient for this purpose, whatever be the amount of the policy. It would also appear that the copy policy does not require to be authenticated with a shilling stamp.

The means adopted of getting the duty assessed were as follows:

The original policy, kindly lent us by the re-assuring office, was lodged at Somerset House, together with our guarantee endorsed upon a copy of it. We were then required to stamp our guarantee with a sixpenny stamp, and supply the authorities with a copy of the original policy, endorsed with a copy of our guarantee, and after some delay our guarantee was returned to us marked-
Commissioners
2,926 .
of Inland Revenue
$13 \mathrm{Jun}, 9$.
Adjudged duly stamped.

I did not understand that any special form or style of guarantee would be insisted on, the view taken by Somerset House being, it seemed, that a re-assurance in this form was of the nature of an indemnity.

I thought of raising the question as to the stamp duty on an ordinary policy granted by one office to another and bearing a re-assurance endorsement, but did not do so at the moment, thinking 
1889.] The Institute of Actuaries.—Syllabus of Prizes. 167 such a course might perhaps upset the whole negotiation. I propose to do so at a later date.

I am, Sir,

Your obedient servant,

Legal and General Life Assurance Offce,

E. COLQUHOUN.

10, Fleet Street, London, E.C.

24, July 1889.

[It appears probable that if the agreement by the re-assuring company were under seal a 10s. stamp would be necessary. The agreement above referred to would be under hand merely.Eo. J.I.A.] 